\title{
ABORDAGEMTERRITORIAL DO RURAL E O DILEMA EM CONCEITUAR CAMPO
}

\author{
Claudio Machado Maia*
}

\begin{abstract}
Resumo
O objetivo deste artigo é demonstrar o dilema na conceituação do campo e do rural no Brasil, no qual, após exaustiva revisão bibliográfica teórico-empírica em torno da caracterização da ruralidade numa abordagem territorial, apresentamos a agricultura e sua afirmação como atividade determinante da estrutura rural e como eixo articulador de economia diversificada. Dessa forma, o rural passa a incorporar áreas dispersas e concentrações urbanas que se explicam por sua relação com os recursos naturais, considerando a diversidade de setores econômicos interdependentes, envolvendo dimensões econômicas e não econômicas, estabelecendo relações funcionais de integração com o urbano e fundamentando-se em visão territorial. A questão que persiste é: conceituar-se campo implica em diferenciar-se do rural? A ruralidade pode ser considerada como a apropriação do campo ao rural, considerando-se as economias de escala geradas a partir das atividades não agrícolas?
\end{abstract}

Palavras-chave: Rural. Campo. Ruralidade. Território.

\footnotetext{
* Doutor em Desenvolvimento Rural pelo Programa de Pós-Graduação em Desenvolvimento Rural da Universidade Federal do Rio Grande do Sul, UFRGS. Mestre em Desenvolvimento Regional pelo Programa de Pós-Graduação em Desenvolvimento Regional da Universidade de Santa Cruz do Sul, UNISC. Professor do Programa de Pós-Graduação em Políticas Sociais e Dinâmicas Regionais - Universidade Comunitária da Região de Chapecó, UNOCHAPECÓ - Santa Catarina, Brasil. E-mail: claudiomaia.dr@hotmail.com.br
} 


\section{Contextualização: uma trajetória para a redefinição}

Neste ensaio, a organização da fundamentação teórica considerou a transição e a mudança que vem ocorrendo nas últimas décadas, quando o mundo presenciou o desmoronamento de paradigmas que dominaram os argumentos e modelos de atuação do poder político, das empresas, das academias, dos intelectuais, dos tecnocratas e do poder local, adotados até então. Neste artigo é analisada a nova ruralidade, como proposta que visa conceituar rural, e o desenvolvimento rural sob uma perspectiva diferente das que predominam nas estratégias da política dominante nos governos e organismos internacionais.

Apoiada no colapso de paradigmas, a busca de um novo paradigma apoia-se na necessidade de enfrentar a realidade no mundo rural e a refletir sobre a realidade desse mundo, um território imerso na mais ampla gama de problemas, com potencialidades e desafios sem conta (PERICO; RIBEIRO, 2005, p.11).

Com a nova ruralidade, pretendem-se avançar na integração dos desenvolvimentos conceituais e políticos das últimas décadas e em sua possibilidade de instrumentação, como ferramentas que potencializem a gestão de instituições e governos e permitam novos debates da inclusão diante da exclusão, da equidade diante das desigualdades sociais, étnicas e de gênero, e da valorização dos espaços rurais como continuidade do urbano (PERICO; RIBEIRO, 2005, p.15).

Dadas a força da tradição e as condições de aproveitamento dos recursos naturais, e apesar da emergência de novos setores econômicos, na maioria dos países da América Latina, e principalmente no Brasil, a agricultura continua como atividade determinante da estrutura rural e como eixo articulador de economia diversificada. $\mathrm{O}$ que vem a confirmar a importância dos cenários comerciais a serem enfrentados pela economia agrícola, que não consegue encontrar seu verdadeiro papel e posicionamento, nos espaços cada vez mais disputados de uma economia internacional mais aberta, que se move num cenário de negociações complexas, de assimetrias e distorções, que se expressam em grandes debilidades da economia rural, agrícola e não agrícola.

Conforme Perico e Ribeiro (2005, p.19), a nova ruralidade está centrada, como proposta integral, sob três fundamentos de diferenciação, de complemento ou reforma profunda das políticas 
predominantes na atualidade. $\mathrm{O}$ primeiro refere-se à redefinição do âmbito da ação da política rural; o segundo, à necessidade de revisar a fundo a questão da economia rural; e o terceiro, à necessidade de propor nova institucionalidade rural.

Partindo da redefinição do rural, a nova ruralidade convida a reconsiderar a visão de que o rural é população dispersa centrada no setor agropecuário, para passar à reconstrução do objeto de trabalho e de política - o que implica, necessariamente, redefinir a economia que suporta os territórios - ao definir o âmbito rural como território construído a partir do uso e da apropriação dos recursos naturais, onde são gerados processos produtivos, culturais, sociais e políticos. Processos que são gerados pelo efeito da localização e apropriação territorial, compreendendo-se aí, que os recursos naturais são fatores de produção localizados. Dessa forma, o rural passa a incorporar áreas dispersas e concentrações urbanas que se explicam por sua relação com os recursos naturais, considerando a diversidade de setores econômicos interdependentes, envolvendo dimensões econômicas e não econômicas, estabelecendo relações funcionais de integração com o urbano e fundamentando-se em visão territorial.

Tal redefinição de ruralidade reivindica profundas revisões nas políticas oficiais, assumindo-se a necessidade um novo conceito de planejamento territorial e descentralizado, contrapondo-se ao atual e predominante planejamento setorial e centralizado. Vem a ser uma inovação em termos políticos, ao propor que a autonomia dos territórios rurais e sua própria capacidade de autoinstitucionalização fundamentam nova forma de gestão do desenvolvimento. Proposta sustentada na necessidade de construir verdadeira cidadania rural.

$\mathrm{O}$ enfoque territorial da nova ruralidade entende a aproximação da economia dos recursos naturais com a economia do território, incluindo, nas funções de crescimento e desenvolvimento, aspectos como a economia ambiental e ecológica, os mercados de serviços ambientais, a sustentabilidade dos sistemas produtivos, os recursos genéticos, as redes de solidariedade social, os conhecimentos e a cultura, a equidade de gênero e a inclusão étnica e etária como parte de economia mais complexa que agrária, que domina o cenário da política pública.

Essa visão inovadora da economia rural, reconhecendo os novos setores econômicos e suas externalidades, propõe uma revisão dos critérios de valorização da eficiência econômica a partir da 
ampliação do conceito de competitividade que orienta as estratégias e os conceitos de vantagens competitivas da economia rural.

Com a redefinição e crítica da eficiência como problema restrito à produtividade privada, quando se incorporam as externalidades, ou seja, os benefícios sociais das atividades produtivas rurais, é possível incorporar o conceito de competitividade social como expressão de economia de eficiência que cumpra cabalmente as retribuições que este tem para o conjunto social, incluindo os empresários e rendimentos privados, mas não limitando sua valorização a este âmbito. A competitividade social permite realinhar os termos de intercâmbio e de negociação, em nível global, do comércio rural e das vantagens comparativas e/ou competitivas dos territórios rurais. Realinhamento da economia que proporciona instrumentos para o aproveitamento dos esquemas de economia de mercado, predominantes no capitalismo global atual, em beneficio da maioria das populações rurais (PERICO; RIBEIRO, 2005, p. 20).

Para concretizar os eixos fundamentais da proposta sobre a nova ruralidade, requer-se revisar a institucionalidade para o desenvolvimento dos territórios rurais. Reconhece-se a transição atual, marcada por macroprocessos simultâneos, como a mudança nas competências e funções do território, do local ao global, centrada em dois eixos complementares de mudança institucional: a descentralização e a globalização, enquanto ocorrem mudanças nas responsabilidades de âmbito público e privado - processos de redefinição do papel do Estado nacional e de participação e privatização de funções públicas. Tendências que dominam o espaço de renovação institucional, ultrapassando a visão da engenharia institucional predominante e incorporando com maior ênfase a dimensão política.

Uma concepção integral da economia institucional que permite fazer a aproximação de um mercado de políticas públicas onde predomina uma visão de oferta pública a uma proposta de mecanismos reais que conduzem a uma estratégia de demanda. O que implica numa redefinição das regras do jogo, de incentivos, de mecanismos de transação, de novo papel do Estado e redefinição profunda do papel das organizações da sociedade civil, dos indivíduos e das comunidades. Tal redefinição de funções que inclui a visão institucional da nova ruralidade abre espaço à incorporação de estratégias para instrumentar reformas institucionais coerentes com as mudanças e forças sociais, 
econômicas e políticas que condicionaram as possibilidades de desenvolvimento institucional efetivo.

A reorganização de competências, funções, responsabilidades e instituições do território é o centro de uma proposta de renovação institucional para o território rural. As competências da estrutura hierarquizada e viva dos níveis locais, subrregionais subnacionais, nacionais, regionais supranacionais, hemisféricos e globais estão se redefinindo de forma a revelar as grandes debilidades e os vazios que formam uma nova agenda de ajustes.

\section{Ruralidade: a abordagem do rural segundo a perspectiva do espaço e do território}

A concepção de territorialidade rural a partir da revalorização do espaço rural e de sua geografia como unidade de gestão que integra uma realidade econômica multissetorial e dimensões políticas, sociais, culturais e ambientais que vêm construindo uma institucionalidade dinâmica, oferece possibilidades de respostas às muitas falências apresentadas ao desenvolvimento rural nas últimas décadas. E o esforço será ajustar políticas rurais setoriais apoiadas no território, incorporando a dimensão espacial na definição de políticas públicas.

A definição do rural como território leva à reflexão sobre o desenvolvimento atual e futuro, o processo histórico de apropriação territorial que ocorreu nas Américas apoiado basicamente na atividade agrícola. Processos de colonização que se desenvolveram em torno da agricultura. Diferentes formas de exploração agrária que permitiram a incorporação de territórios considerando suas possibilidades e condições, resultando na conformação de grupos sociais e de suas respectivas tradição, cultura, instituições e expressões políticas as quais deram lugar à formação de nações.

A ruralidade é esse habitat construído durante gerações pela atividade agrícola; é o território onde esse setor formou uma sociedade. Esse conceito considera uma visão multidisciplinar que abrange aspectos antropológicos, sociopolíticos, ecológicos, históricos e etnográficos e, além da tradicional visão econômica da agropecuária e do rural, considera a visão setorial que predomina nas estratégias de política rural.

Ao se considerar o rural como território, busca-se o enfoque integraldasociedaderuraleadinamizaçãodesuasprópriaseconomias, o que possibilitará o avanço em nova concepção de políticas públicas. 
Tal concepção é pertinente, pois se baseia na evidência de que a maior parte das políticas públicas aplicadas nos territórios rurais latino-americanos contemplam parcialmente os elementos que constituem essa visão integral de ordem regional e territorial (PERICO; RIBEIRO, 2005).

A tradição e a história têm permitido construir culturas que incorporam cosmovisões particulares, linguagens, formas de relação, valores estruturados em torno de uma moral, princípios étnicos, sentido de participação e identidade. A visão territorial propõe revalorizar esse elementos, dando-lhes espaço adequado e incorporando-os às políticas de desenvolvimento rural, fortalecendo, protegendo e preservando as culturas rurais.

As expressões de organização social e da base cultural das populações rurais são suas próprias instituições, marcando o ponto de partida da nova institucionalidade. Institucionalidade rural como produto da evolução das instituições naturais construídas no tempo pelos povoadores rurais.

A ruralidade, para Verde (2004), é considerada ao analisar o território a partir de um recorte analítico, teórico e metodológico que considera, na redescoberta do rural a partir nos anos de 1990, a importância no entendimento da necessidade de pontuar, na formulação de sua base conceitual, aspectos como a interpretação das atividades rurais e seus desdobramentos, num espaço onde as relações sociais são consideradas historicamente, considerando as dimensões espacial, ambiental, demográfica e cultural. Com os elementos presentes na discussão do território, possibilitando avançar teórica e metodologicamente na compreensão do rural inserido numa economia globalizada. $\mathrm{O}$ autor conclui que, para a construção e definição de territórios, uma possibilidade seria partir do reconhecido e da diversidade econômica e social presente na sociedade estudada, por exemplo, seu processo histórico e de construção de uma identidade cultural.

Verde (2004,p.4) descreve que a observação e análise do rural passam de um enfoque setorial para uma abordagem territorial. Com o território assumindo um papel crescente como recurso analítico e unidade de planejamento e intervenção, substitui-se a noção de região cuja interpretação é sujeita a um maior grau de arbitrariedade em sua definição.

Neste contexto, as reflexões sobre desenvolvimento feitas a partir da dimensão local são tomadas como válidas para a discussão da dimensão territorial. A partir da hipótese de que um 
território abriga mais de um local - hipótese adotada quando se quer falar ou destacar uma atividade ou grupo social em particular. E perceptível nos estudos que tratam sobre desenvolvimento local que esse recorte é elástico: ora refere-se a um conjunto de municípios, ora é utilizado como sinônimo de município.

Entende-se que o rural, além de agrário, da economia agrícola, envolve quatro dimensões para sua compreensão. Uma espacial, uma ambiental, uma demográfica e uma cultural - Cada uma dessas dimensões com suas análises específicas. Dimensões que possuem reciprocidade, pois atuam combinadas. Deixa-se claro que o espaço é compreendido no tempo porque este lhe dá sentido. "Por tempo, vamos entender grosseiramente o transcurso, a sucessão dos eventos e sua trama. Por espaço, vamos entender o meio, o lugar material da possibilidade dos eventos" (SANTOS, 1993, p. 19).

Para a proposição de rural apresentada por Verde (2004), convém apresentar alguns conceitos elaborados, particularmente, pela sociologia e por teóricos do desenvolvimento. Entre os grupos que discutem os conceitos de rural e urbano no Brasil e suas implicações, estão os que seguem a tendência mundial assumindo a tese do continuum rural-urbano, representado pelo grupo do projeto Rurbano - coordenado por Clayton Campanhola e José Graziano da Silva.

A tese do continuum rural-urbano assume o rural e o urbano entendidos como um continuum, uma vez que o rural se urbanizou devido ao desenvolvimento e à aplicação de técnicas industriais na agricultura; com o urbano transbordando culturalmente para o rural; com a existência de processo de valorização do apelo ambiental do rural pelos habitantes dos centros metropolitanos urbanos demandando ocupações urbanas no rural; um mercado de trabalho que possibilita à família rural obter outras fontes de renda além da atividade agrícola; apontando para um aumento da renda rural decorrente das rendas provenientes da atividade não agrícola. $\mathrm{O}$ continuum rural-urbano é entendido como uma relação que aproxima e integra dois polos, revalorizando as representações sociais do rural e do urbano (VEIGA, 2003).

A dimensão ambiental do rural é dada pela sua relação com a atividade agropecuária, em termos de preservação e paisagem. Do ponto de vista conservacionista, no espaço rural, o meio ambiente relaciona-se diretamente com a produção, exigindo-se uma exploração criteriosa. Complementarmente, o meio ambiente 
passa a ser apreendido também como paisagem, ao proporcionar alternativa para as áreas com baixa aptidão produtiva, porém, com potencial para o comércio e/ou serviços, como o turismo rural ou de aventura, por exemplo. Tal percepção de consumo, da natureza, remete ao aspecto patrimonial implícito no meio ambiente, o que implica uma legislação e política pública que dê conta dessa particularidade (VERDE, 2004, p. 11).

Os parâmetros de densidade demográfica, utilizados em diversos países são os mais variados. A heterogeneidade do critério pode ser compreendida dada a diversidade de situações existentes. O desafio é definir critérios que possam de fato revelar o quanto a variável população ajuda a entender e definir o espaço rural.

Veiga, a partir da análise do Censo de 2000, propõe que se considere município de pequeno porte, ou seja, rural, aquele que tenha simultaneamente menos de 50 mil habitantes e menos de $80 \mathrm{hab} / \mathrm{Km}^{2}$. Proposta que tem o mérito de permitir uma observação do espaço rural de maneira mais abrangente, embora nesse trabalho tenha adotado, como critério, municípios com menos de 20 mil habitantes por entender ser essa medida mais adequada à realidade rural paranaense.

Além do aspecto quantitativo presente na variável demográfica, uma variável qualitativa, o aspecto cultural das sociedades como a dimensão simbólica da vida cotidiana, é extremamente diversificada. O que leva a considerar uma noção de conceito de cultura como um conjunto organizado de indivíduos com um determinado modo de vida. A cultura é esse modo de vida. A cultura como o agregado de pessoas e as relações sociais entre essas pessoas. A cultura como enfatizando a composição de recursos acumulados, imateriais e materiais, que as pessoas herdam, empregam, transmutam, acrescentam alguma coisa e que transmitem.

O rural assim entendido deixa de ser o espaço, por excelência da produção agrícola. Alarga-se, envolvendo pequenas e médias cidades. $\mathrm{O}$ modo de ser rural se faz presente no campo e na cidade e passa a ser denominado ruralidade (VERDE, 2004, p. 19).

O conceito de ruralidade está em construção, e por ser um conceito em construção, permite um emprego sintonizado com pressuposto do desenvolvimento.

A ruralidade é um conceito territorial que pressupõe a homogeneidade dos territórios agregados sob essa categoria analítica, e isto naturalmente vale também para o conceito de urbano. Ainda que não contíguos, os territórios rurais compartem, de fato, algu- 
mas características comuns que no entanto não foram definidas de maneira clara nem no que concerne aos indicadores que devem ser utilizados, nem no que se refere ao limite que deveria distinguir o rural do urbano. $\mathrm{Na}$ maior parte dos casos, o que é rural e o que é urbano vem intuitivamente reconhecido e depois medido. Com frequência (sic) tem-se sustentado que a diferença é de natureza social e relativa ao modo como estão distribuídas as populações e as cidades no território, ou francamente cultural, tanto que nenhum órgão oficial empenhado nessa tarefa (Nações Unidas, OCDE, U.E., Escritórios de Estatística) tem conseguido encontrar uma definição que satisfaça a todos, ainda que por tempo limitado (SARACENO, 1996 apud VERDE, 2004).

Conforme Verde (2004, p. 19), aceitar um conceito em construção impõe precauções adicionais quando aplicado conceitual e operacionalmente. A ruralidade, tal qual o território, representa a oportunidade de incluir, ampliar, absorver o que tem se mantido fora, alargando horizontes, não naturalmente, mas dependentemente da decisão política de assim ser.

\section{O campo e as implicações da ruralidade}

O camponês é o habitante e produtor no campo (campagna, em italiano; cittadino, cidadão, habitante da città, cidade). Em países onde ocorreu a mudança entre o feudalismo para o capitalismo, campesinos eram aqueles "com terra" ou "sem terra" que exerciam atividades produtivas, artesanais e agrícolas no campo.

Neste sentido, trabalhar com o conceito de campo implica em algumas questões. Destacamos duas:

a) dependendo da abordagem que se faz, no trato da relação cidade-campo, tendencia-se para a dicotomização urbanorural, já que a cidade e o campo são feitos de edificações/ obras, enquanto que o urbano e o rural são efetivados por relações sociais. É claro que não há obras sem relações e nem relações sem obras, o que faz com que o campo também possa ser entendido como relações;

b) o campo nos remete, necessariamente, à existência de camponeses, seus habitantes e produtores agropecuários.

O marco histórico na utilização do conceito de camponês e campesinato no Brasil é a década de 1950, inicialmente pelo debate político em torno das lutas dos trabalhadores no campo, e depois pelos embates teóricos dentro da ciência social brasileira. 
Porto (1997) afirma que é a partir deste período que se pode falar de uma questão agrária brasileira, e, que o rural se constitui de forma mais sistemática como objeto teórico e empírico de estudos, e se afirma enquanto problema político.

Naquele momento, foram importadas as teorias construídas a partir da análise de trajetórias históricas europeias e, em especial, sobre a situação da Rússia no fim do século XIX e início do século XX. Do conceito clássico de camponês, podem-se resgatar algumas características básicas que configuram uma estrutura particular da sociedade. Cardoso (1987) destaca quatro: 'A primeira é um acesso estável à terra, ou na forma de propriedade, ou mediante algum tipo de usufruto. A seguir o trabalho predominantemente familiar, o que não exclui o uso de força de trabalho externa, de forma adicional. A terceira característica seria a autossuficiência combinada a uma vinculação ao mercado, eventual ou permanente, e, que o objetivo está na realização de trocas por produtos utilizados no consumo da família. Por último, está a presença de certo grau de autonomia na gestão das atividades agrícolas, ou seja, nas decisões sobre o que e quando plantar, como dispor dos excedentes, entre outros' (CARDOS0, 1987, p. 56-57).

Wanderley (1999, p. 29-30) também destaca esse aspecto da autonomia, de caráter demográfico, social e econômico, e enfatiza a capacidade da economia camponesa em promover a subsistência imediata e a reprodução da família pelas gerações futuras. Segundo a autora, essa especificidade no sistema de produção camponesa e a centralidade na constituição do patrimônio familiar formam as características fundamentais do campesinato clássico. Outro aspecto essencial na compreensão do camponês tradicional, é seu sistema produtivo do tipo policultura-pecuária. A diversificação de culturas configura-se como parte da estratégia adotada pela família camponesa, que tem na combinação com a criação de animais sua alternativa de fertilização dos solos e melhoria na produtividade dos cultivos.

Essas características do campesinato europeu, e a não identificação integral das mesmas características no caso brasileiro, deram margem a um forte debate na década de 1960, pondo em questionamento a real presença de camponeses no Brasil. Embora a retomada do debate não seja o foco desse estudo, neste momento, dá-se o inicio das discussões em torno de o que seria essa face do rural, a ruralidade. 


\section{Considerações finais}

Antes da retomada das discussões em torno das particularidades no campo brasileiro, o mesmo era caracterizado como lugar onde havia predomínio de atividades agrícolas e agropecuárias. A produção dependente das condições da natureza e realizada para fins de consumo ou subsistência da comunidade e da localidade onde era produzida, podendo haver comercialização, em baixa escala ou escambo, porém para fins de garantia das condições de consumo em termos da subsistência, e não para o comércio per se.

Era de senso comum não existir no campo a possibilidade de se identificar, por exemplo, serviços ambientais incorporados a uma função de produção econômica ou a um espaço de interação de serviços num território. Não haveria como mensurar eficiência econômica ou suas implicações, a produtividade, a rentabilidade ou mesmo competitividade, ou associar a uma caracterização de território em termos de uma base produtiva, uma vez que a produção nem mesmo era considerada para fins de comércio.

O campo não tinha origem ou efeito no território, consequentemente não se referia às inter-relações entre setores econômicos e dimensões do desenvolvimento. A pobreza era um problema dos indivíduos, e a busca de sua solução ou alívio era feita dentro do setor agrícola, pelos próprios indivíduos, ou via emprego agrícola, ou com a mudança do local de cultivo do produto ou monocultura, de um determinado lugar para outro.

Porém, a ruralidade como hoje é referenciada, resgata uma ampla discussão em torno da abordagem de território e da sua oferta de possibilidades variadas de modelos e sistemas produtivos, como expressão de sua diversificação e da integração de mercados, determinando alternativas de produção, de organização e desenvolvimento. $\mathrm{O}$ emprego não agrícola é uma expressão dessas possibilidades. $\mathrm{O}$ que não significa que as estratégias de desenvolvimento sejam cada vez menos agrícolas, pois o setor mantém seu papel de articulador da territorialidade rural.

\section{Referências}

CARDOSO, Ciro Flamarion S. Escravo ou camponês? O protocampesinato negro nas Américas. São Paulo: Brasiliense, 1987.125p.

PERICO, Rafael Echeverri; RIBEIRO, Marília Pilar. Ruralidade, Territorialidae e Desenvolvimento Sustentável. Brasília: IICA, 2005. 
PORTO, Stela Grossi (org.). POLITIZANDO a tecnologia no campo brasileiro: dimensões e olhares. Rio de Janeiro: Relume-Dumará, 1997. 226p.

SANTOS, Milton. O novo mapa do mundo: tempo e espaço mundo ou, apenas, tempo e espaço hegemônicos? Trabalho apresentado no 17\% Encontro Nacional da ANPOCS. Caxambu: ANPOCS, 1993.

VEIGA, José Eli da. Cidades Imaginárias: o Brasil é menos urbano do que se calcula. Campinas: Autores Associados, 2002.304p.

VEIGA, José Eli da. O que é rural? O que é urbano? Rumos. Rio de Janeiro: ABDE, v.28, n.212, p.4-8, nov./dez.2003.

VERDE, Valéria Villa. Territórios, Ruralidade e Desenvolvimento. Curitiba: IPARDES, fev. 2004.

WANDERLEY, Maria de Nazareth Baudel. Raízes Históricas do Campesinato Brasileiro. In: TEDESCO, João Carlos (org.). Agricultura Familiar: realidades e perspectivas. Passo Fundo: EDIUPF, 1999. p. 23-56.

\title{
TERRITORIAL APPROACHTO RURAL AND THE DILEMMA IN CONCEPTUALIZING COUNTRYSIDE
}

\begin{abstract}
The purpose of this article is to demonstrate the dilemma in conceptualizing the field and the rural in Brazil, where after exhaustive literature review, theoretical and empirical around the characterization of rurality in a territorial approach, we present agriculture and its affirmation as determining activity of rural infrastructure and its central theme diversified economy. Thus the rural areas will incorporate dispersed and urban concentrations due to its relationship with natural resources, considering the diversity of economic sectors interdependent, involving economic and non-economic dimensions by establishing functional integration with the urban and relying in territorial vision. The questions that remain are: Does conceptualizing up field imply differentiate yourself from the countryside? Can the rurality be considered as the appropriation of the rural countryside, considering the economies of scale generated from non-agricultural activities?
\end{abstract}

Keywords: Rural. Countryside. Rural Life. Territory.

REVISTA GRIFOS - N. 32/33 - 2012 